\title{
La nueva dinámica de la condición social moderna
}

[New dynamic of modern social condition]

\author{
Danilo Martuccelli \\ Université Paris Descartes
}

\section{Resumen}

El artículo propone una reconceptualización de la dinámica de la experiencia de la condición social moderna contemporánea. Se procede en tres grandes etapas. En un primer momento se precisan las especificidades de la matriz de la condición moderna y sobre todo la importancia que tuvo en ella el advenimiento de lo social. En segundo lugar, se argumenta que en las sociedades actuales se asiste a una inflexión de la dinámica central de la condición social moderna en torno a la vida en común y las singularidades. En tercer lugar, y luego de evocar ciertas consecuencias normativas de este proceso, se indican algunos de los principales desafíos que esto acarrea en la teoría y el análisis sociológico.

Palabras clave: Modernidad; experiencia; social; común; singularidad.

\begin{abstract}
This article proposes a reconceptualization of the dynamics of the experience of contemporary modern social condition. The argument will be developed in three steps. Firstly, we will present the matrix of the modern condition and above all the importance that the advent of the social had in it. Secondly, it will be argued that in cotemporaries societies has taken place an inflection of the central dynamics of modern social condition concerning common life and singularities. Thirdly, after evoking some normative consequences of this process, the main challenges to sociological theory that this processes entail will be discussed.
\end{abstract}

Keywords: Modernity; experience; social; common; singularity.

Contacto: La comunicación sobre este artículo debe ser enviada a Danilo Martuccelli, email: danilo.martuccelli@parisdescartes.fr 


\section{INTRODUCCIÓN}

La modernidad ha sido asociada a un periodo histórico (los tiempos modernos), a una forma de conocimiento o un espíritu intelectual (la ciencia moderna, la Ilustración), a un movimiento artístico (el modernismo), a un tipo de sociedad (sociedad moderna), a un modo de desarrollo (la modernización). Si las diferencias son notorias, algo es común a todas estas caracterizaciones: la modernidad es inseparable del primado del sujeto y de la subjetividad en términos cognitivos (racionalismo o empirismo), políticos (derechos humanos), religiosos (la conciencia protestante) o morales (la autonomía). En este sentido es posible afirmar que la modernidad definió, tras el primado del individuo, una experiencia inédita: la conciencia de una ruptura particular entre lo objetivo y lo subjetivo.

Es a partir de esta concepción que en este artículo caracterizaremos a la modernidad como una experiencia particular del ser conjunto -la condición social moderna. Como lo veremos, a diferencia de sociedades marcadas por lo político o la moral, la modernidad se caracteriza por la invención de lo social. Entre el Estado y la vida doméstica se yergue lo social -la sociedad civil, las políticas sociales, las asociaciones, la civilidad y el urbanismo, el consumo, la legitimidad de la vida personal, familiar y económica a distancia de los deberes ciudadanos. Comprender y analizar la modernidad, exige otorgarle, así, a lo social una innegable centralidad analítica.
Las razones del triunfo de lo social son estructurales y bien conocidas incluso si no siempre se extraen todas las consecuencias que esto implica. Lo social en efecto no ha cesado de acentuarse. Piénsese en el hecho que si en año 1800 sólo el 3\% de las personas vivían en entornos urbanos, hoy esa proporción supera al $50 \%$, que el gasto público en porcentaje del PIB que, en los países desarrollados, era menos del $10 \%$ en 1850 , hoy oscila entre $35 \%$ y $55 \%$; a lo cual habría que añadirle la expansión de los controles (el uso de los pasaportes solo se generaliza tras la primera guerra mundial); la expansión de la regulaciones administrativas (piénsese en la alimentación); o la multiplicación de las asociaciones. Desde este punto de vista, la situación de los clásicos de la sociología entre fines del siglo XIX y comienzos del siglo XX, difiere radicalmente de la situación contemporánea. Lo social define siempre la experiencia de los individuos, pero lo hace desde coordenadas radicalmente distintas. El argumento central de este artículo será sostener que lo que ha variado en este lapso es la experiencia del ser conjunto, la manera de sentirnos miembros de la vida social, y que ello implica un importante trabajo de revisión teórica. Procederemos en tres grandes etapas. Comenzaremos caracterizando la noción de condición social moderna para luego, en un segundo momento, adentrarnos en lo que constituye hoy en día su dinámica central (lo común y lo singular), y terminaremos evocando rápidamente algunos de los desafíos que esto entraña para el trabajo sociológico (cf. Martuccelli, 2017a). 


\section{La condición social moderna}

La condición social moderna (CSM) es una forma inédita de experiencia de la vida colectiva construida entre el fin del siglo XVIII y comienzos del siglo XIX, en torno a la representación de un individuo viviendo en sociedad. Desde las primeras formulaciones de la experiencia moderna, como en Hegel o en la novela, la distancia entre lo objetivo y lo subjetivo se vuelve la cuestión central. La ruptura -el fin de la totalidad- da forma a la condición social moderna como experiencia y como representación.

\section{La CSM: una experiencia histórica inédita}

Afirmar que el individuo vive en una sociedad no es en absoluto una perogrullada. Si se dejan de lado interpretaciones demasiado modernizadas de la afirmación aristotélica del hombre como zoon politikon, es claro que el individuo de la época antigua no vive en una sociedad sino en la Polis, y que lo hará más tarde en una Comunidad de creyentes, un Imperio o un Reino, pero no necesariamente en una sociedad. La experiencia del ser conjunto se definió durante siglos a partir de los regímenes políticos. Por supuesto esto no impidió la existencia de una vida privada, el comercio, o una vida ética a distancia de la política, pero en la antigüedad el hombre, en su lazo con el ser conjunto, estuvo esencialmente definido desde la polis.

En contraste y a veces en oposición, el cristiano -si retomamos la división de Agustín - vive en dos ciudades. Traducción de la cuestión del alma y del cuerpo, esta representación estructuró la legitimidad del conflicto entre las dos espadas -el papa y el emperador. Detrás de esta tensión subyacía el desequilibrio fundador del cristiano que viviendo en la ciudad terrestre debía orientarse en función de la ciudad celeste. En oposición al zoon politikon, puede decirse que el hombre cristiano es más moral que político. Sin embargo, en estas dos grandes experiencias del ser conjunto, la tripartición entre los que rezan, los que hacen guerra y los que trabajan fue de rigor durante milenios. Y los que trabajan fueron ampliamente desconsiderados con respecto a los otros dos.

Los tiempos modernos cambian radicalmente esta situación. Progresivamente un ámbito, en verdad una experiencia específica del ser conjunto se constituye. En la modernidad, entre la política y la moral, se desliza progresivamente lo social. Este dominio comprende, por supuesto, el trabajo y el comercio, pero incluye también a la sociedad civil, las asociaciones, la vida familiar o amistosa, más tarde las prácticas culturales, el consumo de masa o las diversiones. En el siglo XIX, las interpretaciones de lo social se multiplican muchas veces en lazo con la cuestión social (Donzelot, 1984), pero progresivamente su importancia, y su novedad, se imponen.

Si lo inédito de esta experiencia del ser conjunto no escapa a sus mejores analistas -comenzando por Hegel- la especificidad de lo social se revela a veces difícil de aprehender, velada por las transformaciones del mercado y la impronta de 

condición social moderna. Revista de Sociología 32(1), 89-105. doi: 10.5354/0719-529x.2017.47887

la separación entre lo público y lo privado. Lo social será así muchas veces asociado con la política (como en la cuestión social) o con el ámbito privado (como en tantos liberales o moralistas). Pero es justamente la doble autonomía de lo social con respecto a la política y a la moral, la manera particular como atraviesa y recorta lo público y lo privado, lo que constituye su novedad. Tal vez nada exprese mejor el advenimiento de lo social, y la toma de conciencia de esta novedad, que el arte de la novela, el que, desde el siglo XVIII, inventa al personaje social. La descripción de las peripecias y sobre todo la explicación de la conducta de los actores se hace a partir de su posición social. Imposible minimizar la radicalidad de esta nueva gramática: si durante siglos fueron los caracteres (la avaricia, la hipocresía, los celos, el amor) lo que definió a los protagonistas, en la modernidad la íntima comprensión de los actores será indisociable de lo social (Barrère \& Martuccelli, 2009).

A pesar de su mirada crítica, la novedad de lo social fue particularmente bien comprendida por Arendt (1995), para quien la política es la capacidad de crear un mundo común entre los individuos con el fin de organizar la pluralidad humana y la reciprocidad entre seres diferentes. "La política en el sentido estricto del término no se refiere a los hombres sino al mundo que hay entre ellos" (Arendt, 1995, p. 154). Sin la construcción de esta forma de unidad de la diversidad, sin esta transformación de la pluralidad humana en mundo común, la vida colectiva sufriría una profunda amputación.
Esto es justamente lo que ha sucedido, según Arendt, en los tiempos modernos. El advenimiento del dominio social se habría traducido por el eclipse de la política y su disolución en la pura gestión, por la invasión de la esfera pública por los problemas privados, de índole sobre todo económicos. Arendt es consciente que la razón de esta dificultad proviene del ingreso de los esclavos, sometidos a las necesidades materiales, en el mundo común. "El solo hecho que se haya emancipado a las mujeres y a las clases laboriosas, es decir a grupos que no habían jamás aparecido en la vida pública, confiere un rostro radicalmente nuevo a todas las cuestiones políticas" (Arendt, 1995, p. 111). Pero si es consciente de esta novedad, Arendt escamotea e incluso rechaza las consecuencias que ello entraña. A sus ojos, el ingreso de las cuestiones de vida personal en el espacio público signa, sin más, su crisis. Arendt afirma así su franca oposición a una visión de la política como satisfacción de necesidades vitales, a la idea que la tarea de la política consistiría "en garantizar la vida en el sentido más amplio" (Arendt, 1995, p. 67).

Para Arendt, la regla parece clara: la vida y la propiedad pertenecen a la necesidad, no a la libertad. La afirmación es sorprendente. El dominio de la propiedad, el orden de la necesidad, se ha convertido en objeto de mirada política y de conflicto social en la CSM, y en este sentido sometido al trabajo de la libertad que los individuos se otorgan unos a otros. A menos que se defienda una concepción particular de las relaciones entre la economía y la Polis -o del Estado y del mercado-, o sea, se transmute una 
etapa histórica en un ideal normativo del ser conjunto -lo que hace Arendt-, no hay ninguna razón para excluir de la política cuestiones relativas a la vida, la propiedad o la necesidad. Si evocamos los estudios de Arendt es porque ejemplifican mejor que muchos otros los impasses de una buena parte de la filosofía política para comprender la experiencia de lo social en la modernidad y la importancia adquirida por el trabajo (Arendt, 1994), y tras él, y más allá de él, la vida social ordinaria. En verdad, Saint-Just, bajo el impulso de su juventud, estaba más cerca de la verdad cuando afirmó con énfasis que el bonheur era una idea nueva en Europa. Por supuesto, se puede, con Arendt, condenar esta deriva, pero al hacerlo el análisis renuncia a comprender uno de los grandes rasgos de la modernidad, a saber, la centralidad de la cuestión de la vida de los individuos y su vínculo con la expansión de lo social.

Aunque no siempre lo afirmó con la fuerza necesaria, la sociología nace de una toma de distancia radical con la mirada de la filosofía política. El régimen político cesa de ser el marco de interpretación de los fenómenos sociales en beneficio de la sociedad y lo social. Montesquieu podía todavía, en 1748, explicar la fortuna y la miseria de los países por la naturaleza de sus regímenes políticos; en 1776, Adam Smith da cuenta de estas diferencias a partir de la dinámica de la economía, ella misma concebida como un intercambio generalizado e interno a la sociedad.

\section{La CSM: una mirada específica}

El reconocimiento progresivo de esta nueva experiencia del ser conjunto da lugar a nuevas interpretaciones. Si la vida social siempre se ha desarrollado en grandes conjuntos sociohistóricos, no es sino hasta el siglo XVIII, en Occidente, que se impone paulatinamente la representación particular de la idea de sociedad. Si el término de sistema para describir este modus operandi es tardío, la idea de una interdependencia coercitiva, e incluso necesaria, entre las diferentes funciones de una sociedad se encuentra ya en la base de las miradas que los primeros economistas -que no se llamaban, por lo demás, así en aquella época- dan de la vida social en torno a la articulación entre producción, circulación y consumo. A la visión piramidal y estática de los regímenes políticos (según la cual cada quien debía quedarse en su lugar), le sucede una representación que no solamente reconoce la dinámica de la vida social, sino que erige al movimiento en valor colectivo. Comprendámoslo bien: la idea de sociedad no es una realidad material evidente, por el contrario, se trata de una representación que le otorga al conjunto una capacidad efectiva de institución práctica de los fenómenos sociales (Touraine, 2013; Dubet \& Martuccelli, 2000; Dubet, 2009).

Durante mucho tiempo la idea de sociedad fue la principal respuesta que la sociología dio al maelstrom de la modernidad. O sea, en el momento mismo en que reconocía la profundidad de la experiencia fundadora de la modernidad (la separación entre lo subjetivo y 
lo objetivo), la sociología intentó evacuar (o por lo menos limitar) esta realidad a través de la idea de sociedad en tanto que nueva totalidad (Martuccelli, 2014). En este marco, los sociólogos clásicos si bien nunca se desinteresaron de las especificidades de la experiencia de vivir en sociedades, nunca le dieron un rol protagónico. En el mejor de los casos, los análisis iban de la sociedad a la experiencia. El estudio se limitó así a considerar las consecuencias que a nivel de los individuos tenían los grandes cambios sociales (la anomia, la caja de acero, la alienación).

Sin embargo, progresivamente la CSM, incluso si muchas veces de manera solo subrepticia, ha terminado impulsando una perspectiva de análisis particular - una mirada que partiendo de la experiencia de la vida social intenta comprender las estructuras de la sociedad. Una estrategia de estudio que no escamotea las dimensiones macro-sociológicas pero que las aborda de otra manera -en sentido inverso- a como lo hace la idea de sociedad. Si el estudio bajo la impronta de la idea de sociedad hizo del Estado-nación el verdadero perímetro de la interpretación sociológica, en la perspectiva de la CSM lo central es aprehender la estructura de la experiencia de la vida en sociedad. Autonomizar intelectualmente la experiencia de la CSM exige partir de las vivencias de los individuos con el fin de ponerlas en relación con los grandes cambios estructurales de un período, sin reducirlas a ellas. El va y viene entre experiencias y estructuras da así lugar a una visión particular del ser conjunto, diferente de la que se construye desde la idea de sociedad.
El retrato de una sociedad desde la experiencia de los individuos es particular: no se seleccionan los mismos factores, no se construyen las mismas cartografías (para el caso chileno, cf. Araujo \& Martuccelli, 2012). En realidad, no solamente los factores tomados en consideración son diferentes, incluso los factores estructurales que son comunes a estas perspectivas (idea de sociedad o experiencia social) son aprehendidos de manera distinta. Estudiar los fenómenos colectivos desde las experiencias de los individuos estimula una forma particular de la imaginación sociológica (Mills, 1967), una manera sui generis de articular vivencias personales, estructuras sociales e inquietudes históricas (Martuccelli, 2015).

Instaurar la experiencia de la vida en sociedad como foco de pregnancia de la interpretación, exige transitar de la concepción abstracta de un individuo que estaría en el origen del contrato social hacia un individuo concreto estudiado como el resultado de una manera de hacer sociedad. Es lo esencial: la experiencia de la CSM es inseparable del advenimiento de lo social, en verdad, y para ser más exactos, de un proceso creciente e irreversible de societalización de las vidas personales. La societalización no es un vocablo oscuro para designar el zoon politikon de Aristóteles; es una manera de designar un nuevo estadio histórico de la experiencia del ser conjunto. Esta realidad define la dinámica de la CSM desde sus inicios: por un lado, un proceso creciente y continuo de societalización de las existencias; por el otro, y como consecuencia paradójica de este proceso, la acentuación de un sentimiento de 
distanciamiento creciente de los individuos con la sociedad (Elias, 1991).

Por supuesto, el sentimiento de extrañeza frente al mundo no es específico de la modernidad. Muchos otros factores, comenzando por la acción performativa de ciertas representaciones espirituales o subjetivas dan cuenta de esta experiencia. Pero, si el sentimiento de exterioridad con respecto al mundo no es propio a la modernidad (Ferrater, 1965; Barel, 1984), en la modernidad, y esto sí es una novedad, esta experiencia va a ser interpretada como la consecuencia, más o menos directa, de un proceso histórico. Es en la modernidad y solo en ella que, por un lado, se le otorga una centralidad inédita a las cuestiones propiamente existenciales (desde Kierkegaard) y que, por el otro, se propone una versión plenamente societal e histórica de ello (Martuccelli, 2017b). Toda la fuerza y los meandros infinitos de la temática identitaria en la modernidad, tan bien reflejados en la novela moderna (de Balzac à Roth, pasando por Joyce, Woolf o Proust), apunta justamente a dar cuenta de esta experiencia histórica de disociación. La experiencia moderna, como Berman (1982) lo ha magníficamente ilustrado, hace de los individuos a la vez los sujetos y los objetos de las transformaciones.

Resumiendo, la condición social moderna caracteriza una experiencia particular e histórica del ser conjunto, asociada al advenimiento de lo social, indisociable de la ruptura de la totalidad y de la oposición entre lo subjetivo y lo objetivo. Es dentro de este marco que, como lo veremos, es necesario comprender la inflexión contemporánea.

La CSM actual: la dinámica de lo común y lo singular

Para dar cuenta de la experiencia contemporánea de lo social es preciso transitar de la ecuación entre el individuo y la sociedad hacia la dinámica de lo común y lo singular. La forma histórica de la experiencia del ser conjunto hoy se inscribe así en inflexión -o sea, en continuidad, pero con un cambio relativo de rumbo- con respecto a la experiencia fundadora de la ruptura moderna. Las experiencias de la vida social hoy, altamente existenciales $\mathrm{y}$ societales, deben pues leerse en un primer momento en la estela de lo propio de la CSM desde sus orígenes. Nada connota mejor la continuidad de esta experiencia que la increíble permanencia del sentimiento de los modernos de vivir en una época bisagra, de vivir una ruptura histórica inédita, de vivir en medio de un mundo donde lo viejo muere y lo nuevo tarda en nacer. En verdad, de experimentar una distancia hacia la sociedad y al mismo tiempo de sentirse englutido en un torbellino social del cual es imposible salir. Es esto lo que es central, desde sus orígenes, en los análisis sociológicos de la modernidad en torno a la tensión entre el individuo y la sociedad. Sin embargo, el reconocimiento de la pregnancia centenaria de este sentimiento debe tomar en cuenta el hecho que hoy en día éste se declina de manera particular y con una intensidad muy distinta: los individuos se sienten cada vez más 
Martuccelli, D. (2017). La nueva dinámica de la condición social moderna. Revista de Sociología 32(1), 89-105. doi: 10.5354/0719-529x.2017.47887 apresados por la sociedad y al mismo tiempo tienen el sentimiento de estar cada vez más desinsertos en ella. Cambio de grado y tal vez no de naturaleza, pero que no por ello obliga menos a un profundo trabajo de revisión teórica. En todo caso, los individuos se sienten -y son- cada vez más movilizados de manera coercitiva en la sociedad y al mismo tiempo sienten que son, cada uno de ellos, irreductiblemente distintos. $\mathrm{O}$ sea, el individuo se vive, en su singularidad la más íntima y personal, como irreductible a la vida social, y al mismo tiempo el individuo se vive como indisociable de la vida colectiva.

Esta dinámica y su tensión recorre toda la vida social: en el trabajo, por ejemplo, en donde el imperativo de la cooperación cohabita por doquier con la necesidad de distinguirse; en el consumo en donde la movilización coercitiva se impone antes, durante y después del acto de compra (capturar la atención, fidelizar la clientela); en las instituciones a las cuales los ciudadanos les exigen cada vez más un trato personalizado; a través de las TIC que nos familiarizan con la doble relación constante con el gran mundo y con un pequeño mundo que gira en torno a nosotros mismos. La experiencia de la ruptura de lo objetivo y lo subjetivo, sin desaparecer, es subsumida por la intensidad de la dinámica del enrolamiento coercitivo en la vida social.

Por supuesto, esta estructura general de la experiencia del ser conjunto difiere fuertemente según los ámbitos (familia, trabajo, espacio urbano), en función de los perfiles de los diversos actores, según se trate de relaciones conflictivas o colaborativas, de interacciones cara-a-cara o a distancia. Pero esta diversidad no debe servir de coartada para no analizar la existencia de una experiencia transversal en la CSM actual.

En todo caso, ahí donde la ecuación individuosociedad subrayaba, según las perspectivas, la relativa independencia de cada término o su fuerte imbricación, la dinámica en curso entre lo común y lo singular subraya el carácter inevitable y problemático de la experiencia del ser conjunto.

Curiosamente, en la teoría social contemporánea la dinámica entre lo común y lo singular tiende muchas veces a ser leída de manera disociada. Por un lado, y desde perspectivas teóricas muy distintas, se insiste en la exterioridad de los individuos con respecto a los sistemas sociales (Luhmann, 1995) o en la necesidad de abandonar lo social en beneficio del sujeto (Touraine, 2013). Por otro lado, desde diversas teorizaciones de las redes (Castells, 1998; Latour, 2006; White, 2001), se insiste en el gran número y en la pluralidad de las conexiones y de los lazos, pero éstos son disociados por lo general de toda consideración vivencial.

La experiencia de la CSM actual está marcada por la expansión de una conciencia societalizada de sí que es irreductible a otras formas de conciencia social -sobre todo aquella definida por Durkheim (1986) en torno a la solidaridad orgánica. En el análisis de Durkheim la interdependencia que liga los hombres entre sí es en mucho abstracta, más deducida que vivida. Es ésta la razón por la cual se vio obligado a subrayar, al lado de la división del 
trabajo u otras interdependencias morfológicas, la importancia de formas de relación más visibles y concretas, como los cuerpos intermediarios, las instituciones o los valores compartidos. La dinámica de lo común y lo singular da lugar hoy a formas infinitamente más carnales y evidentes, y ello en todos los ámbitos de la vida social. La societalización de la existencia es un rasgo central del mundo contemporáneo en donde, por ejemplo, en muchas sociedades europeas el número de hijos está relacionado con el tipo de políticas públicas, en donde la salud y la educación tienden a ser -con fuertes variantes nacionalesmás que nunca cuestiones sociales, y lo mismo podría decirse de las cuestiones ecológicas. Cada individuo toma conciencia en lo más ordinario de su vida de todo lo que ella le debe a los otros y a la sociedad en la que vive. Una realidad que invita a redefinir las nociones de común y de singular.

La vida en común

En las ciencias sociales, la noción de común ha estado por lo general asociada con la idea de mundo común, con un horizonte que se instituye, por ende, vía lo político ${ }^{1}$. En todos estos trabajos, lo común implica así tanto una comunidad política como formas activas y políticas de participación. En el fondo, lo común así teorizado se opone muchas veces a lo social.

1 Si dejamos de lado formulaciones clásicas, como la ya evocada de Arendt, en el panorama contemporáneo la noción de común ha sido movilizada en este sentido, común entre otros por Ostrom (2010), Hardt y Negri (2012), Dadort y Laval (2014) o Nancy (2013).
Repensar lo común desde la CSM impone una toma de distancia con estas concepciones. Lo importante es aprehender la experiencia inmanente y ordinaria de la vida social, el hecho de vivir en sociedad en intercambio $y$ en dependencia con los otros (Fischbach, 2015). Una experiencia que, como lo hemos indicado, se caracteriza, en todos los ámbitos de la vida social, por una dinámica simultánea de movilización y de distanciamiento.

En medio de sociedades cada más diferenciadas y plurales, los individuos comparten cada vez menos un mundo común, y al mismo tiempo tienen la experiencia permanente de vivir en común. Esta última caracterización le da una importancia analítica innegable a los intercambios mercantiles, sin subordinar empero el lazo social a esta única realidad. Lo que hace es rechazar la idea que es necesario construir lo común a distancia, en verdad, en oposición al mercado. La dificultad del pensamiento social en incluir al mercado en la comprensión -descriptiva y normativa- de la vida social es sin duda uno de los grandes escollos de las ciencias humanas y sociales (Honneth, 2015). Cuando esta dimensión es tomada en cuenta -de Marx a Habermas, pasando por Polanyi- lo es por general con el fin de subrayar los efectos patológicos del mercado capitalista: fetichismo de la mercancía, sociedad de mercado, colonización del mundo de la vida. $\mathrm{Al}$ realizar esta elección crítica, muchas representaciones de este tipo evidencian problemas para comprender la experiencia efectiva y ordinaria de la vida social. El elogio y la nostalgia- de la comunidad, de los grupos 
en fusión, de las corporaciones, de los consejos obreros, o de la democracia directa no tiene, en el fondo, otro origen. El ideal es sistemáticamente construido en alteridad con respecto al mercado.

Por el contrario, el pleno reconocimiento de que la vida social se desenvuelve muchas veces en universos en común, en donde los individuos están más yuxtapuestos que mezclados, invita a darle a la estructura de los intercambios mercantiles un rol analítico más importante a la hora de comprender la CSM actual. Evitemos todo malentendido: el mercado no da en absoluto forma a todas las relaciones sociales. Pero la impersonalidad a la cual se han acostumbrado los individuos en la CSM hace de esta modalidad de relación social una experiencia generalizada $\mathrm{y}$ frecuente del ser conjunto e incluso, en parte, un horizonte normativo de las interacciones.

Sin embargo, si el mercado ha sido sin duda un factor importante en la consolidación de la experiencia de la vida en común, no ha sido, por supuesto, el único factor. La vida social se vive por doquier en común, como cuando, por ejemplo, los individuos se descubren similitudes esporádicas en tanto que consumidores de un producto o espectadores de una emisión cultural. Pero también, cuando lo hacen en tanto que usuarios regulares de un medio de transporte en común; cuando participan en un proyecto en común o en una empresa manteniendo empero su implicación a niveles bajos; cuando forman parte, sin compromiso particular, de un grupo estudiantil o de camaradería; incluso cuando en medio de una red familiar personalizan sus afectos o instituyen distancias con otros familiares; sin olvidar, todas las reuniones o asociaciones que se viven con personas distintas y anónimas en lugares públicos.

Por supuesto, estas formas de participación en común no excluyen la existencia de agrupaciones más cohesionadas o colaborativas (de la familia a las organizaciones), pero éstas no son en absoluto la norma. En realidad, lo inverso es infinitamente más justo: islotes de mundo común en el sentido fuerte del término se despliegan en el océano de la vida en común. La vida social no se reduce pues a actitudes de voice, exit o loyalty (Hirschman, 1970); lo que quedó fuera de esta tríada son justamente las experiencias las más ordinarias y las más frecuentes, cuando los individuos, sin gran compromiso, actúan en común. Contrariamente a tantas letanías críticas y pánicos morales, la generalización de la vida en común no ha significado ni el fin de la civilidad, ni del bien común, ni de la sociedad. Por supuesto, es legítimo aspirar a formas más intensas de comunicación o de cooperación, pero esto no debe en ningún momento hacer descuidar la importancia - para no decir la centralidad- de las situaciones en común en la CSM actual, en donde los individuos se agrupan al tiempo que se ignoran recíprocamente. Ésta es una experiencia ordinaria que el uso de las TIC y la creciente coordinación sociotécnica de las acciones vuelve cada vez más frecuente.

La dificultad en reconocer plenamente esta realidad se explica por la remanencia de la noción de comunidad. Las declinaciones son 
distintas según se trate de la nación, la etnia, el género, la clase o la familia, un colectivo de trabajo o una asociación política, pero en todos los casos se afirma siempre una preferencia normativa por los lazos fuertes y cooperativos. Bajo esta mirada, el resto de la vida social es analizada con circunspección, incluso con un matiz crítico. Sin embargo, cuando el análisis se centra en las dinámicas efectivas del ser conjunto, es obvio que no es necesariamente este horizonte el que estructura las experiencias sociales.

El siglo XX ha sido el teatro de la desaparición de una cierta ingenuidad colectiva: aquella que, como en ciertas frases de Marx, asocia como una evidencia no problemática el desarrollo de todos con el de cada uno. En todas las visiones de la comunidad en el sentido más amplio del término (grupos en fusión, fraternidades) existe en efecto la ilusión de una articulación, no problemática, entre lo individual y lo colectivo. La historia del siglo pasado obliga a reconocer de manera infinitamente más ambivalente la consistencia de la vida social y sus dificultades. En el ordinario de sus vidas, los individuos, sin recusar la cooperación, se muestran reticentes hacia los colectivos -de los sindicatos hasta el estado, hacia los líderes tanto como hacia los aparatos, en dirección de los anónimos como de los conocidos. Ni de la misma manera, ni con la misma intensidad, pero para muchos individuos del siglo XXI el entusiasmo virginal hacia los grupos es cosa del pasado.

A causa de esta actitud, el análisis de la vida en común siempre tuvo una tonalidad crítica. La vida en común, incluso si la designación fue poco empleada, renviaba a una asociación aleatoria de individuos, una reunión externa y efímera, como entre los oyentes de una emisión de radio (Sartre, 1985) o las alienaciones en la circulación automovilística en donde los individuos se cruzan sin encontrarse (Lefebvre, 1968), y más recientemente las descripciones de los individuos co-aislados o solos juntos en sus usos de las TIC, sin olvidar las experiencias de coexistencia espacial y de distancia social. Con variantes, el razonamiento es siempre el mismo: la vida en común sin mundo común conlleva a un inevitable aislamiento individual. Pero al adoptar esta actitud crítica, estos análisis son incapaces de comprender a cabalidad los rasgos de la vida en común y las experiencias efectivas que del ser conjunto tienen hoy los actores sociales. Se revelan sobre todo incapaces de comprender la fuerza de movilización y de enrolamiento presentes en las distintas experiencias de la vida en común.

La singularidad como existencia

La noción de singularidad no es una realidad unívoca. La noción puede ser asociada a lo que es poco frecuente o a lo excelente, a lo diferente o lo excéntrico, a lo curioso o lo extraordinario, a lo que asombra o desentona; puede también designar lo original o lo inexplicable e incluso lo que es aislado; lo extraño, lo insólito, lo inesperado o lo raro; y por supuesto, en una lista que podría alargarse a lo que es único o fuera de toda medida (L'Inactuel, 2004). Sin embargo, para hacer de la singularidad una herramienta de análisis de la CSM actual, es 
necesario tomar distancia de la mayor parte de estos empleos, pero sobre todo de aquellos que asocian la singularidad con la originalidad, la diferencia o la ejemplaridad. En estos tres casos, en efecto, la noción tiende a desolidarizarse de toda afiliación colectiva en beneficio de lo único, lo diverso o lo sin norma. Para comprender el lazo entre la singularidad y lo común hay que construir la noción a partir de sus bases existenciales.

En todo caso, la asociación exclusiva o prioritaria de la singularidad con la originalidad, la diferencia o la ejemplaridad priva a la noción de toda carga significativa para comprender la sociedad contemporánea. En el mejor de los casos la noción es reservada a algunos, y rechazada por definición a la gran mayoría. Estos empleos de la noción de singularidad suponen una ruptura con toda idea de imitación, lo que se revela demasiado radical para dar cuenta de un sinnúmero de experiencias sociales (Gomá, 2014). La singularidad, en su sentido sociológico, es incompatible con la idea de una creación heroica. Pensada desde la ejemplaridad (moral), la diferencia (identitaria) o la originalidad (artista) la singularidad es concebida en oposición, no sin contradicciones, a la imitación, lo similar o lo ordinario. En los tres casos, se opone a lo común. La separación de la masa aparece como el gran rasgo constitutivo de lo singular que pareciera no tener así otro lazo con el colectivo o lo ordinario que el de su distinción. Definiendo la singularidad de preferencia a nivel del individuo y su genio personal o identitario, el análisis oblitera el hecho que es la sociedad la que hace o no posible y bajo ciertas modalidades la singularidad.

Estas conceptualizaciones impiden comprender las manifestaciones sociales más frecuentes de la singularidad en la CSM actual y, sobre todo, el verdadero desafío que plantea al análisis sociológico, a saber, que se trata antes que cualquier otra cosa de una cuestión propiamente existencial. Mientras que la originalidad y la diferencia se destacan de lo común, y la ejemplaridad debe llevarlo a su excelencia, la singularidad como existencia se imbrica con lo común.

La dificultad a la hora de aceptar esta visión de la singularidad proviene de la impronta de las lecturas artistas, identitarias o ejemplares que han tendido a asociarla con lo extravagante, la espontaneidad, la autenticidad, o sea, una vez más con la originalidad, la excelencia, la diferencia -en muchos casos, notémoslo, en lazo con una idea de la genialidad, que ella sea política, artística, intelectual o moral. En esta acepción, la singularidad es percibida como una amenaza a la vida social a la vez que se la representa bajo amenaza, en su realidad misma, por la tendencia a la homogeneidad de los colectivos.

La situación es muy distinta cuando se piensa la singularidad desde la existencia. La cuestión de lo concreto se vuelve un rasgo indisociable de la singularidad en tanto que dimensión inexpugnable del hecho mismo de existir (Bodei, 2013). La singularidad, en su lazo con la individuación, aquello que permite justamente el devenir individuo, se vuelve una categoría para analizar los colectivos en sus capacidades 
- o no- para hacer posible la concreción de cada singularidad.

Seamos claros: en esta interpretación lo excepcional de la singularidad reside en su existencia, puesto que la verdadera rareza se encuentra en la existencia. "Cada singularidad es un otro acceso al mundo" (Nancy, 2013, p. 32). Un otro acceso, propio a cada cual, perfectamente particular, irreductible a toda alteridad, el que es preciso comprender así fuera de todo horizonte de originalidad, de diferencia $o$ de ejemplaridad. Ninguna genialidad anida en esta noción de la singularidad; pero la noción no designa por ello menos una irreductibilidad radical. La singularidad, toda singularidad es, para retomar la expresión de Agamben (1990), una singularidad cualquiera, o sea una cuestión de pertenencia (y de existencia) y no de identidad. La relación consubstancial con lo común aparece así claramente. Entendida de esta manera, la singularidad interroga tanto las ventajas o los obstáculos específicos y comunes del medio en el que se produce, sus recursos o sus potencialidades, como sus encarnaciones individuales; un ser, todo ser, solo se pueden individuar participando en un grupo, en un colectivo que lo engloba y que constituye en este sentido su verdadero fondo pre-individual (Simondon, 1989), una dimensión por la cual, el singular, constituyéndose como tal, se vincula con el conjunto. Es en este sentido que la vida individual es siempre en común; la irreductible singularidad existencial de cada cual solo es posible à partir del común del cual participa.
Este aspecto no es nuevo, pero la dinámica de la CSM le da un peso muy distinto. En el pasado fue frecuente que las vidas se desarrollen en universos homólogos. Tras nacer en un pueblo, los actores frecuentaban la escuela del villorrio, se casaban con un vecino, trabajaban en la principal fábrica del sector, poseían una sociabilidad restringida, y consumían productos altamente estandarizados. Hoy en día, sin que este tipo de experiencias haya desaparecido, se impone una singularización creciente de las trayectorias. Es cada vez menos probable encontrarnos con clones sociológicos, o sea, con individuos que han tenido las mismas experiencias, en los mismos lugares, en los mismos momentos, con las mismas personas. La diversificación de experiencias es la regla y tras ella se afirma la expansión de la singularidad. Ningún diferencial de genio sociológico entre nuestros antepasados y nosotros: hoy como ayer, los individuos están bajo la impronta de condiciones sociales e históricas, pero ahí donde ayer el proceso de individuación acentuaba la estandarización, hoy consolida la singularización.

Sin este desplazamiento nocional, la singularidad es -ha sido- una agonía sociológica. Lo importante en el marco de la CSM es pues comprender la formación histórica y estructural, bajo una modalidad existencial, de la cuestión de la singularidad con el fin de dar cuenta, desde la sociología, de lo que esta exigencia implica para entender la sociedad actual. Es porque un conjunto de factores estructurales complejiza la relación entre lo singular y lo común a nivel de la producción 
industrial, del consumo, de los ideales institucionales, de las industrias culturales, de la diversificación identitaria o de los lazos sociales que la cuestión de la singularidad se convierte en uno de los pilares de la experiencia ordinaria de la vida social (Martuccelli, 2010). La sociedad exacerba la irreductible particularidad de cada cual.

Las singularidades en común: un programa sociológico

Si las principales representaciones históricas del individuo no han cesado de sostener una desconfianza hacia la sociedad, la dinámica de lo singular y lo común produce una experiencia distinta del ser conjunto. Comprender las manifestaciones de este vínculo inevitable $\mathrm{y}$ problemático entre la singularidad y la vida en común es un programa de investigación cuyo objetivo es mostrar cómo las singularidades no preexisten a su puesta en común y, a su vez, como lo común no abole jamás las inquietudes por la singularidad. Puede incluso decirse que esta dinámica diferencia entre una cuestión ontológica y una cuestión axiológica, y, por esta vía, reabre la discusión entre liberalismo y socialismo.

Para los liberales, sin sorpresa, la axiología de la singularidad es fundamental: ya John Stuart Mill (1990), en su libro de 1850, De la libertad, hacía de la individualidad intrínseca un valor al punto de plantear como gran objetivo social el desarrollo singular y específico de cada individuo. Stuart Mill defenderá una concepción dinámica de la individualidad como proceso, posibilidad, promesa de realizar dones y talentos útiles a la sociedad que, precisa como buen liberal social, no pueden desarrollarse sino gracias a la educación, la familia y las instituciones. El ideal de la individualidad apunta así al desarrollo de la más rica diversidad humana -única, original, auténtica-, una concepción que en el caso de Stuart Mill se opone al conformismo y a la uniformidad, pero que no por ello requiere menos de los recursos de la vida social para poder explayarse. La fuerza del pensamiento de Stuart Mill consiste en hacer del pluralismo individual el objetivo axiológico explícito del pluralismo político liberal. Un siglo y medio después, esta concepción, no sin reticencias y oposiciones, se ha convertido en uno de los principales ideales de la CSM. Sin embargo, y al mismo tiempo, el vínculo entre la libertad individual y sus presupuestos sociales no ha cejado de ser problemático en esta tradición -como lo muestran, por ejemplo, los debates en torno a la herencia y el mérito (o sea ¿cuánto de la realización personal se debe en realidad a los colectivos?).

La situación es distinta en un autor como Karl Marx. En efecto, el marxismo -y más ampliamente el pensamiento socialista- en su voluntad por comprender las condiciones materiales de existencia de los individuos, ha afirmado claramente el primado de la ontología de la vida social sobre la axiología de la singularidad. En verdad, nunca se desinteresó de ésta, y el marxismo siempre subrayó la necesaria articulación entre desarrollo social y 
libre emancipación de cada cual. Pero el peso no fue similar.

El ser humano comienza solamente a individualizarse a través del proceso histórico. En el origen, aparece como un ser genérico, ser tribal, animal de manada -pero en absoluto como un zoon politikon en el sentido político. El intercambio es un factor mayor de esta individualización. Hace superfluo el sistema de la manada y lo disuelve. A partir del momento que la situación ha tomado esta dirección, en la cual el ser humano en tanto que individuo singularizado solo se refiere a sí mismo, los medios para plantearse como un individuo singularizado se vuelven el acto por el cual se hace universal y común (Marx, 2011, p. 456).

La idea de una articulación necesariamente virtuosa, más allá de las divisiones creadas por el mercado, entre la comunidad social y las libertades individuales tampoco ha dejado de ser, desde entonces, problemática en el horizonte del socialismo.

Las acentuaciones son distintas y no se trata de reconciliarlas, sino de mostrar de qué manera, esta venerable oposición ideológica, se plantea en términos renovados en la CSM contemporánea. En cierto sentido, la dinámica de lo singular y lo común nos confronta con una situación que va más allá de lo que evocaron el liberalismo y el socialismo, y que algunos trabajos denominan como individualismo holista (Pettit, 1993). Es porque se apunta y se reconoce la singularidad de cada uno que es preciso pensar en las condiciones de la existencia para todos; es porque se parte del primado ontológico de lo común que se defiende normativamente la singularidad. Para existir el individuo requiere de un conjunto de infraestructuras y de soportes que, más allá de lo que pertenece a la vida social per se sociabilidad, relaciones, lenguaje- comprometen una cierta modalidad de relaciones sociales trabajo, educación, formación, salud, arte, ciencia. La axiología y la ontología han terminado (no sin dificultad ni riesgos) por articularse en la CSM en torno a una pregunta fundamental: ¿cómo asegurar colectivamente para todos, la posibilidad de existencia singular de cada uno?

En este proceso, la libertad negativa (y el hecho de encontrarse al abrigo del arbitrario político) por importante que sea no es sino una de las condiciones, entre otras, de la singularidad. La singularidad en común traza así una profunda diferencia con la visión liberal clásica. El individuo, incluso cuando adhiere con fuerza al imaginario de un yo autónomo e independiente, no puede, en la CSM actual, sino reconocer en lo más concreto y ordinario de su vida personal su imbricación y dependencia con un conjunto de relaciones sociales. La sociedad puede ser percibida como una amenaza por el individuo; no es menos por ello el marco de su existencia. Todos los individuos, de manera muy evidente en muchas sociedades europeas, dada la fuerza del Estado social nacional, tienen conciencia de lo inevitable del lazo -siempre problemáticoentre ellos y su sociedad, pero se trata de una realidad planetaria, el 60\% del ingreso de una persona depende del país en el que el azar le hizo nacer (Bregman, 2017). Lo anterior obliga 
a reconocer las dependencias de cada uno con los colectivos y la sociedad, y no solamente respecto de algunos otros significativos. Todos los individuos retiran siempre de los colectivos los recursos para su existencia. Todos retiran de lo común los medios necesarios a su existencia y en este sentido la propiedad privada o el mito del Self made man no cambian nada a esta realidad. Por supuesto esta dependencia no data de hoy, pero hasta hace muy poco tiempo esto permitió visiones a la Robinson Crusoe y anhelos utópicos de fuga. En el mundo de hoy, dada la extensión y la intensidad del proceso de societalización ello se vuelve imposible. Se impone el reconocimiento que lo singular es indisociable de lo común. Pueden por supuesto existir diferentes dinámicas (virtuosas o perversas), pero no puede haber una oposición radical permanente entre ambas dimensiones.

La fuerza de esta dinámica exige un verdadero aggiornamento teórico de muchas de las más venerables cuestiones de la teoría social (para un desarrollo, cf. Martuccelli, 2017a). La oposición entre la sociedad y la comunidad debe dar paso al estudio de formas de implicación afectiva en donde, a causa de la dinámica entre lo singular y lo común, cada vez más todo lo que es social es percibido como personal. Debe hacerlo, tanto más que, en todos los ámbitos sociales, con una fuerza inusitada, los individuos se sienten prisioneros de formas intensas de movilización generalizada y coercitivas (trabajo, consumo, ritmos temporales, TIC). También porque la cuestión clásica de la integración de la sociedad (ya sea la integración sistémica o la integración social) exige ser repensada en los términos de una coordinación sociotécnica de la acción que al tomar cada vez más independencia con respecto al ideal de un mundo común plantea, sobre nuevas bases, la coexistencia de heterogeneidades $\mathrm{y}$ pluralismos. $\mathrm{O}$, para señalar otra arista, debido a que en la estratificación social el lazo inevitable y problemático entre lo común y lo singular alimenta un conjunto diverso de inquietudes y experiencias posicionales (movilidades, incongruencia estatutaria, inconsistencia posicional, temores socio-existenciales), lo que invita a repensar el imaginario de la igualdad en la modernidad y las nuevas tensiones entre singularidad, libertad y la fraternidad. Hay que agregar a lo anterior, por supuesto, el hecho que enfrentamos una profunda modificación de los usos y equilibrios entre las grandes narrativas de las sociedades modernas (ciencia, ficción, prensa e ideologías). Finalmente, porque a medida que la experiencia de la modernidad deja de ser un monopolio occidental, se impone la necesidad de comprender cada modernidad múltiple como una singularidad en común con otras. Es solo asumiendo estos retos teóricos como la sociología de la CSM podrá enfrentar mañana los desafíos del siglo XXI. 
Martuccelli, D. (2017). La nueva dinámica de la condición social moderna. Revista de Sociología 32(1), 89-105. doi: 10.5354/0719-529x.2017.47887

\section{REFERENCIAS}

Agamben, G. (1990). La communauté qui vient. Paris: Seuil.

Araujo, K., \& Martuccelli, D. (2012). Desafios comunes. Santiago: LOM Editores.

Arendt, H. (1994). Condition de l'homme moderne. Paris: Presses Pocket.

Arendt, H. (1995). Qu'est-ce que la politique? Paris: Seuil.

Barel, Y. (1984). La société du vide. Paris: Seuil.

Barrère A., \& Martuccelli, D. (2009). Le roman comme laboratoire. Villeneuve d'Ascq: Septentrion.

Berman M. (1982). All that is solid melts into air. New York: Simon and Shuster.

Bodei, R. (2013). Immaginare altre vite. Milan: Feltrinelli.

Bregman R. (2017). Utopies réalistes. Paris: Seuil.

Castells, M. (1998). La société en réseaux. Paris: Fayard.

Dardot, P., \& Laval, C. (2014). Commun. Paris: La Découverte.

Donzelot, J. (1984). L'invention du social. Paris: Fayard.

Dubet F., \& Martuccelli, D. (2000). ¿En qué sociedad vivimos? Buenos Aires: Losada.

Dubet, F. (2009). Le travail des sociétés. Paris: Seuil.

Durkheim, E. (1896). La division du travail social. Paris: P.U.F.

Elias, N. (1991). La société des individus. Paris: Fayard.

Ferrater Mora, J. (1965). El hombre en la encrucijada. Buenos Aires: Editorial Sudamericana.

Fischbach, F. (2015). Le sens du social. Montréal: Lux.

Gomá, J. (2014). Imitación y experiencia. Madrid: Taurus.

Hardt, M., \& Negri, A. (2012). Commonwealth. Paris: Stock.

Hirschman, A. (1970). Exit, voice and loyalty. Cambridge: Harvard University Press.
Honneth, A. (2015). Le droit de la liberté. Paris: Gallimard.

L'Inactuel (2004). Le singulier (n¹0). Paris: Circé.

Latour, B. (2006). Changer de société, refaire de la sociologie. Paris: La Découverte.

Lefebvre, H. (1968). La vie quotidienne dans le monde moderne. Paris: Gallimard.

Luhmann, N. (1995). Social Systems. Stanford: Stanford University Press.

Martuccelli, D. (2010). La société singulariste. Paris: Armand Colin.

Martuccelli, D. (2014). Sociologías de la modernidad. Santiago: LOM Ediciones.

Martuccelli, D. (2015). Les deux voies de la notion d'épreuve en sociologie, Sociologie, 6, 43-60.

Martuccelli, D. (2017a). La condition sociale moderne. Paris: Gallimard.

Martuccelli, D. (2017b). Sociologia dell'esistenza. Napoli: Orthotes.

Marx, K. (2011). Manuscrits de 1857-1858. Paris: Editions Sociales.

Mill, J. S. (1990) De la liberté. Paris: Gallimard.

Mills, C. W. (1967). L'imagination sociologique. Paris: La Découverte.

Nancy, J. L. (2013). Etre singulier pluriel. Paris: Galilée.

Ostrom, E. (2010). La gouvernance des biens communs. Bruxelles: De Boeck.

Pettit, P. (1993). The Common Mind. Oxford: Oxford University Press.

Sartre, J. P. (1985). Critique de la raison dialectique. Paris: Gallimard.

Simondon, G. (1989). L'individuation psychique et collective. Paris: Aubier.

Touraine, A. (2013). La fin des sociétés. Paris: Seuil.

White, H. (2001). Identité et contrôle. Paris: Editions de l'EHESS.

Manuscrito recibido: 30-11-2017

Manuscrito aceptado: 04-12-2017 